JEAN-NOËL GRANDHOMME

Maître de conférences (HdR) en histoire contemporaine, à l'Université de Strasbourg

Membre des comités scientifiques

du Mémorial de Verdun et du Mémorial

d'Alsace-Moselle

\title{
DES LIEUX DE MEMOIRE AU CEUR DE LA VILLE: LES MONUMENTS AUX MORTS DANS L'EST DE LA FRANCE (ALSACE ET MOSELLE)
}

\section{Introduction}

Entre 1870 et 1945 les Alsaciens et une partie des Lorrains (les Mosellans) ont changé quatre fois de nationalité. Du fait de l'histoire tourmentée de leur région, ils ont porté au cours des deux conflits mondiaux de 1914-1918 et 1939-1945, pour certains l'uniforme français, pour la plupart l'uniforme allemand. En 1918 ils ont terminé la guerre dans le camp des vaincus, mais se sont retrouvés dans celui des vainqueurs en 1919 en vertu du traité de Versailles qui les rendait à la France. En 1940 ils ont subi la défaite comme tous les Français, puis un grand nombre d'entre eux ont été incorporés de force dans l'armée allemande (1942), avant d'être libérés par les armées alliées en 1944-1945. Un humoriste alsacien a pu dire que le seul uniforme qui semble leur avoir toujours convenu est finalement celui de prisonnier de guerre. Comment s'est construite la mémoire d'une telle population? Comment s'inscrit-elle dans la pierre des monuments aux morts qui, au cœur des villes d'Alsace-Moselle, témoignent aujourd'hui encore de la dualité du passé de ces deux provinces? Zone fortement urbanisée, l'Alsace et la Moselle comptent cinq agglomérations principales (Strasbourg, Metz, Mulhouse, Colmar et Thionville), de nombreuses villes moyennes et un dense réseau de petites villes.

Notre étude s'articulera autour de trois thématiques. En forme de prologue, nous mènerons d'abord une réflexion sur les concepts de souvenir et de mémoire dans la société française actuelle, avec leurs incidences sur la région étudiée. Nous envisagerons ensuite les spécificités mémorielles telles qu'elles se présentent en Alsace-Lorraine: empreinte religieuse 
(rendue possible par le maintien du Concordat de Bonaparte dans les trois départements recouvrés par la France en 1919), caractère souvent " neutre » des monuments au point de vue patriotique, bilinguisme parfois de l'épigraphie, ce qui nous amènera à établir un distingo entre les grandes villes - davantage influencées par le modèle national - et les autres. Enfin, nous nous intéresserons aux mutations récentes de la mémoire: monuments aux «oubliés » de l'histoire (Alsaciens-Mosellans morts dans les camps soviétiques, troupes africaines), monuments pacifistes, nouveaux lieux de mémoire.

\section{Souvenir et mémoire dans la société française du second $\mathrm{XX}^{\mathrm{e}}$ siècle}

Pour situer les monuments sur la "scène " sur laquelle ils sont placés dans ce qu'il faut bien appeler le "théâtre de la mémoire », il est d'abord nécessaire de préciser un point de vocabulaire. Car le champ lexical du sujet ne va pas de soi : il ne s'est imposé que progressivement, en suscitant, à juste titre semble-t-il, des réticences qui persistent encore.

Le $\mathrm{XX}^{\mathrm{e}}$ siècle finissant a privilégié la notion de mémoire, qui tend à se substituer au terme, autrefois seul employé, de souvenir. En 1887 le Souvenir français est fondé à Paris par Xavier Niessen, un optant alsacien qui avait refusé de devenir juridiquement allemand après l'annexion de sa province natale par le vainqueur en vertu du traité de Francfort (du 10 mai 1871). Avec pour devise : "À nous le souvenir, à eux l'immortalité », cette association se donne pour but d'entretenir les tombes des «braves morts pour la Patrie» au cours de la guerre de 1870-1871 (c'est d'ailleurs toujours sa mission aujourd'hui, mais se sont ajoutées les tombes des victimes des guerres qui ont suivi, et de nombreux monuments). Se souvenir participe alors du nationalisme ambiant, entretient - au-delà d'une piété naturelle pour des morts qui appartiennent souvent à la famille proche des membres de l'association - le désir de Revanche vis-à-vis de «l'ennemi héréditaire " (le Souvenir français essaime rapidement dans tout le pays, surtout dans l'Est). Les Allemands ne s'y trompent pas, qui interdisent le Souvenir français en Alsace-Lorraine annexée, puis son avatar le Souvenir alsacien-lorrain, après les retentissantes manifestations francophiles qui accompagnent les inaugurations, en 1908 et 1909, de monuments commémoratifs du sacrifice des troupes françaises en 1870 à Noisseville (Lorraine annexée, aujourd'hui Moselle) et Wissembourg (Basse-Alsace, aujourd'hui Bas-Rhin) $)^{1}$.

\footnotetext{
${ }^{1}$ Voir Jean (Jean-Pierre), Le Livre d'or du souvenir français, Metz, 1929.
} 
Se souvenir aurait-il donc conduit les Français à appeler la guerre de leurs vœux, même si l'invasion de leur territoire par l'armée allemande le 2 août 1914 ne leur a finalement plus laissé de choix ? La réponse à cette question n'est pas si simple. Les Québécois, dont la devise est: "Je me souviens ", n'en sont pas pour autant des bellicistes, eux qui ont montré au monde que l'on pouvait faire aboutir des revendications légitimes sans (pratiquement) avoir recours aux armes. Toujours est-il que, de ce côté-ci de l'Atlantique, le mot Souvenir n'avait plus si bonne presse après 1945 : suspect pour les uns, désuet pour les autres. À l'heure de la construction européenne, de la réconciliation franco-allemande, puis de la mondialisation et de la société multiculturelle, les Français préfèrent désormais faire mémoire. La nature des célébrations a d'ailleurs changé elle aussi : on se souvenait des héros, on fait aujourd'hui mémoire de soldats qui, toutes nationalités confondues, sont présentés comme des victimes de conflits qui les ont broyés.

Cette mémoire s'incarne dans des lieux: à cet égard, le livre de Pierre Nora, Les Lieux de mémoire ${ }^{2}$, apparut en son temps comme une révolution dans la manière d'aborder le passé. Mais cette mémoire est aussi sélective. D'âpres débats ont par exemple opposé les historiens français en 1989 sur la nécessité de commémorer avec un faste ostentatoire le bicentenaire de la Révolution, en 1996 sur l'opportunité pour la République laïque de célébrer le mille cinq-centième anniversaire du baptême de Clovis. La mémoire a toujours pour corollaire aujourd'hui la " concurrence des mémoires », d'aucuns se sentant "exclus de l'histoire officielle » et tenant à réintégrer le panthéon national par la grande porte.

La mémoire est devenue un enjeu des passions du moment et, terme qui gêne beaucoup d'historiens, un devoir. Le " devoir de mémoire " n'entretient-il pas indéfiniment les conflits, rétorquent les adversaires de cette pratique ? Loin d'apaiser les querelles, il contribuerait souvent à les perpétuer au sein des nouvelles générations. Le désir de reconnaissance de toutes les composantes de la nation est dans son fondement légitime, mais il est souvent formulé dans une atmosphère passionnelle.

\section{Les monuments aux morts, reflets d'une époque}

Il importe maintenant de définir les contours de cette mémoire ? Combien de livres, de reportages se « vendent-ils » aujourd'hui avec comme sous-titre : " un aspect méconnu » de l'histoire, " oublié par les manuels", ou, mieux encore, "occulté ». La hantise du complot, de la domination mondiale par un petit groupe d'initiés est devenu un argument commercial

\footnotetext{
${ }^{2}$ Paris, 1997.
} 
très porteur. "On nous cache tout! on nous dit rien!", chantait déjà Jacques Dutronc au début des années soixante-dix. La guerre de 19141918, aujourd'hui, très souvent, se réduit aux fraternisations, aux mutineries et aux fusillés pour l'exemple, thématiques phares d'un monde individualisé qui ne parvient plus à comprendre la formidable aventure collective - pour le meilleur et pour le pire, certes - qu'elle constitua en son temps. Pour beaucoup, les monuments aux morts apparaissent alors comme un symbole d'une époque révolue, celle du triomphe de «l'histoire officielle ».

$\mathrm{Au}$ lendemain de la Grande Guerre on élève partout en France des mémoriaux destinés à commémorer le sacrifice des centaines de milliers de jeunes gens tombés sur les champs de bataille. Chaque commune - ou presque - veut le sien, encouragée par l'État, qui accorde des subventions aux plus impécunieuses, mais entend aussi en contrôler l'édification à travers une commission départementale spéciale d'examen technique des projets.

Antoine Prost, dans une thèse pionnière ${ }^{3}$, puis d'autres chercheurs comme Annette Becker ${ }^{4}$, Philippe Rive ${ }^{5}$ ou Jacques Bouillon et Michel Petzold ${ }^{6}$, entre autres, ont entrepris des études approfondies sur ce sujet. De nombreuses enquêtes locales sont menées depuis plusieurs années (qui ont notamment abouti, pour l'Alsace, au mémoire d'Ulrich Päßler ${ }^{7}$ et aux travaux de Marie-Noëlle Denis ${ }^{8}$, et pour la Moselle à l'ouvrage de William $\left.\operatorname{Kidd}^{9}\right)$. Notre travail s'inscrit donc dans cette tradition historiographique. Il s'appuie essentiellement sur le fonds documentaire constitué par les dossiers réalisés sous notre direction par les étudiants de l'université « Marc Bloch » de Strasbourg au cours des années 2000 à 2007.

${ }^{3}$ Les Anciens combattants et la société française, 1914-1939, vol. 3 : Mentalités et idéologies, Paris, 1977.

${ }^{4}$ Les Monuments aux morts : patrimoine et mémoire de la Grande Guerre, Paris, 1988.

${ }^{5}$ Monuments de mémoire. Les monuments aux morts de la Première Guerre mondiale, Paris, 1991.

${ }^{6}$ Mémoire figée, mémoire vivante. Les monuments aux morts, Charenton-le-Pont, 1999.

${ }^{7}$ Denkmalskult im Elsass. Formen Kollektiven Erinnerns nach dem Ersten Weltkrieg, Magisterarbeit, Albert-Ludwigs-Universität - Fribourg-en-Brisgau, 2001 et « Les Monuments aux morts et le culte du souvenir en Alsace après la Première Guerre mondiale » in Eichenlaub (Jean-Luc), Grandhomme (Jean-Noël) (dir.), Août 1942, l'incorporation de force des Alsaciens et des Mosellans dans les armées allemandes, Colmar, 2003, pp. 35-42.

${ }^{8}$ "Monuments aux morts en Alsace. Entre mémoire et histoire », Revue des sciences sociales, $\mathrm{n}^{\circ}$ 30, 2003 : Les Cicatrices de la mémoire, pp. 22-31.

${ }^{9}$ Les Monuments aux morts mosellans, Metz, 1999. 


\section{La christianisation des monuments aux morts d'Alsace-Moselle}

Contrairement à la plupart des monuments aux morts de France, areligieux, ceux d'Alsace et de Moselle sont très souvent christianisés ${ }^{10}$. Il faut y voir les effets conjugués d'une législation particulière : en dépit de nombreuses controverses, l'Alsace-Moselle obtient un statut particulier à l'issue de sa réintégration dans l'espace national. On y parle dès lors de "droit local». Cette particularité législative rend possible la christianisation des monuments aux morts là où, dans le reste de la France (même s'il existe de nombreuses exceptions), une absolue laïcité, c'est-àdire l'absence de tout symbole religieux, est en principe de rigueur. Il faut aussi y voir le résultat d'une importante pression populaire dans une région de forte pratique religieuse. La christianisation des monuments aux morts a cependant encore une autre cause. La plupart des victimes sont tombées sous l'uniforme allemand. Or, l'iconographie religieuse est neutre et offre une alternative aux coqs, poilus, croix de guerre française choisis en d'autres lieux, mais qui ne correspondent pas à la réalité particulière de l'Alsace et de la Moselle.

Dans chaque ville ce sont les conseillers municipaux qui, par un vote, doivent décider de l'emplacement du monument aux morts. Dans la "France de l'intérieur », le choix d'un espace "républicain », d'un espace religieux, ou le compromis (espace neutre) en dit souvent long sur l'appartenance politique de la majorité des habitants au moment de la réalisation. En Alsace-Moselle le monument aux morts s'élève très souvent à proximité immédiate de l'église (en face à Spicheren et à Hoerdt, à côté à Réding et à Abreschviller, le long à Obernai, à Molsheim et à Hochfelden, en contrebas, sous la protection d'une statue monumentale du Sacré Cœur, à Forbach - monument à très nette connotation religieuse que le président de la République, le général De Gaulle, n'a pourtant pas hésité à venir inaugurer en personne en juillet 1961). Il est vrai que la mairie se situe fréquemment aussi à quelques mètres de là : le monument lui fait face dans de nombreux cas, comme à Neuf-Brisach. La plaque commémorative qui fait fonction de monument peut être scellée dans le mur du lieu de culte. Dans d'autres endroits, la situation du monument est moins connotée: devant l'école, par exemple, dans un parc (à Bischwiller, à Sélestat, à SaintLouis, à Munster).

Autre lieu consacré, le cimetière a été choisi par les populations de Sélestat (pour les monuments de 1870-1871 et l'un de ceux de 1914-1918)

${ }^{10}$ Nous traitons ici uniquement des monuments aux morts communaux. Il existe aussi des éléments commémoratifs paroissiaux, dont le caractère religieux ne doit évidemment pas étonner. 
et de Stiring-Wendel. Il n'existe alors plus guère de distingo entre la sphère civique et la sphère religieuse, mais les édiles municipaux ont pris soin de le construire près de la jonction des carrés catholique et protestant. À Dannemarie le monument est installé devant le cimetière militaire. À Lutterbach l'emplacement du monument suscite des controverses, avant qu'un accord ne soit trouvé en 1923 : il est finalement bel et bien construit dans l'espace catholique, à l'intérieur de la chapelle de l'Agonie, dans la basilique du Sacré Cœur. Parfois, le lieu de commémoration de la paroisse précède celui de la commune de plusieurs années, et en fait fonction en attendant, avant de se doubler d'un monument civique.

\section{L'iconographie : une différenciation entre grandes et petites villes}

Dans la plupart des villages d'Alsace et de Moselle, la plus grande partie de la population et donc les autorités communales ne conçoivent pas l'édification d'un monument sans références religieuses. Les symboles chrétiens apparaissent comme des éléments naturels de la commémoration de morts qui, dans leur écrasante majorité, « croyaient au Ciel ». La plupart des villes, comme Phalsbourg, Amnéville, Hagondange, Bischwiller, Mulhouse, Sélestat (pour le monument construit en 1954 à la mémoire des morts de la Seconde Guerre mondiale), Barr, Sarrebourg, Schiltigheim ou Colmar, détonnent cependant: car les monuments aux morts y sont neutres, preuve de la présence de citoyens de confessions et d'opinions politiques différentes, signe aussi d'une volonté de francisation et donc d'alignement sur le modèle de "l'intérieur", sans que cela puisse forcément être interprété comme une marque d'anticléricalisme.

Cette iconographie non religieuse revêt diverses formes, souvent inspirées de l'antique : urne à Maizières-lès-Metz et à Riedisheim, blason de la ville à Mutzig, à Sarre-Union, à Rixheim, à Sarrebourg et à Benfeld, flambeau à Munster, faisceau du licteur et inscription "RF » à Riquewihr, épée à Hayange, couronne de laurier à Lingolsheim, bornes (qui rappellent celles plantées au bord de la Voie Sacrée) à Bischwiller, colombe de la paix à Amnéville, torchère à Merlebach, vasque enflammée à Wintzenheim. Elle met en scène de nombreux personnages: Victoire ailée à Sarralbe, à Sarreguemines et à Riquewihr; Victoire sans ailes mais avec drapeau tricolore à Phalsbourg, femme appuyée sur un bouclier à Sarreguemines (sans doute une allégorie de la France, qui n'a fait que se défendre après avoir été agressée par l'Allemagne), femme en larmes à StrasbourgCronenbourg, femmes affligées également à Schirmeck, à Saint-Louis (femme accompagnée d'un enfant), à Erstein et à Maizières-lès-Metz (couverte d'une coiffe lorraine); femme tenant deux torches allumées à 
Vendenheim; allégories de la Douleur et de l'Espérance à Benfeld, de la Paix et de l'Espérance consolant la Tristesse à Haguenau. A Turckheim six personnages pleurent le mort : ses parents, sa femme et son enfant, son frère et sa sœur. A Altkirch un soldat sans uniforme agonise entre quatre pylones de pierre. A Huningue un homme aussi est représenté, torse nu, émergeant de ce qui pourrait être un drapeau. Un animal revient à plusieurs reprises : le lion (qui rappelle le courage et fait sans doute aussi écho au fameux Lion de Bartholdi à Belfort): à Stiring-Wendel par exemple.

Les symboles patriotiques français ne sont pas totalement absents de l'iconographie d'une Alsace-Moselle qui cherche sa place dans la communauté nationale, même au prix de l'invention d'une histoire en grande partie fictive : la croix de guerre (à Hayange et à Abreschviller), la médaille militaire (à Mutzig), le poilu (à Audun-le-Tiche et à StiringWendel), le casque Adrian (à Sarreguemines-Neunkirch), le coq (à Saales). Le patriotisme français peut aussi être mis en scène de manière plus originale. A Guebwiller une mère embrasse son fils qui part à la guerre, le sac à la main, en lui disant: "Tu es Français, souviens t'en. ». A SainteMarie-aux-Mines un bas-relief représente la « Mère France » retrouvant sa fille l'Alsace. À Mulhouse la statue de la Délivrance vient de se libérer de ses chaînes. A Drulingen, à Hoerdt et à Bouxwiller, en revanche, aucun symbole, pas plus religieux que laïc, n'orne le monument.

Les monuments de Strasbourg, de Brumath et de Metz, quant à eux, apparaissent ambigus car, bien qu'ils ne présentent pas formellement une figure religieuse, leur facture évoque fortement une piéta (à la notable différence près que la mère tient deux fils morts sur ses genoux dans le cas de Strasbourg). Celui de Bitche montre une mère et un groupe de femmes voilées pleurant un jeune homme que deux personnages tiennent dans leurs bras, tableau qui n'est pas sans rappeler la représentation traditionnelle de la descente de la croix. A Amnéville et à Ensisheim également, le groupe central du monument représente une femme tenant un enfant dans ses bras (du type de la Vierge à l'Enfant) et une autre soutenant le corps mort de son fils adulte. La palme, symbole chrétien du martyre, mais aussi plus laïc de la gloire qui auréole les combattants orne les obélisques de Mutzig, de Wasselonne, de Dambach-la-Ville, de Barr et de Merlebach.

A Bischheim c'est un personnage féminin drapé à l'antique (sur le modèle des "vierges et martyres " des livres pieux) qui tient cette palme dans une main. A Schiltigheim, en revanche, ce même personnage découvre l'un de ses seins, ce qui lui donne un caractère nettement profane. 
La croix, sous toutes ses formes, orne de très nombreux monuments christianisés. Tantôt sobre, presque discrète, comme à Maizières-lès-Metz, à Strasbourg-Cronenbourg et à Erstein (sur une urne), tantôt voisinant avec d'autres symboles religieux (étoile de David à Thionville et à Marckolsheim), ou encore ostentatoire. En Lorraine, la croix du même nom, bien que symbole régional (et politique de la France libre, mais cela n'entre pas en ligne de compte dans le cas - le plus fréquent - d'un monument construit dans les années vingt), n'en est pas moins au départ d'essence religieuse: on la retrouve en maints endroits, comme à Grosbliederstroff ou à Yutz; mais aussi en Alsace, comme à Dambach-laVille. A Villé le Christ en croix est entouré de deux personnages masculins et non des traditionnels Vierge Marie et saint Jean. Le réemploi d'un calvaire de 1922 (croix de mission) fait l'originalité du monument de Creutzwald.

La piéta, symbole de la souffrance des milliers de mères qui ont perdu un ou plusieurs fils en 1914-1918, orne un certain nombre de monuments. Le Christ mort - mais qui est appelé à ressusciter - invite les familles à dépasser leur douleur et à placer leur confiance en Dieu qui, un jour, réunira les parents et les enfants séparés. À Saverne et à Andlau une sorte de Mater Dolorosa mi-religieuse mi-laïque est présente, mais debout, tenant dans ses bras un fils mort glabre aux cheveux courts. Il est à noter volonté de ne pas mélanger les genres ou hasard des réaménagements contemporains des places de village ? - que la piéta qui se trouvait au pied du monument de Réding a ensuite été déposée à quelque distance de là, mais toujours dans le voisinage de l'église, comme le monument lui-même. A contrario, le Christ est parfois figuré sans sa mère, comme à Spicheren (statue du Sacré Cœur, dans le style Saint-Sulpice, 1925) ou à StrasbourgNeuhof, où il console une mère éplorée.

D'une manière générale les Anges apparaissent souvent sur le monument, signes visibles de la paix après la fureur des combats. Leur attitude calme et sereine se veut rassurante. Les habitants de Bergheim ont décidé du sexe des Anges. Le leur prend des traits résolument féminins (1925). L'architecte Léon Vallin l'a placé au pied d'un obélisque représentant, écrit-il, "la pensée éternelle, symbole de l'âme qui s'élève vers le Très-Haut, en union perpétuelle avec Lui ». "L'Ange des martyrs ", " dans un geste pieux et glorieux, offre une couronne d'immortelles à la mémoire des chers disparus ». La balustrade qui forme un demi-cercle autour de lui est destinée à "protéger et préserver l'ensemble de toutes les pensées impies ou profanes ».

Les saints, enfin, sont sollicités eux aussi, et d'abord les saints militaires. Héroïne française s'il en est, Jeanne d'Arc est adoptée par des 
communes désireuses de mêler le plus étroitement possible leurs aspirations politiques et religieuses, surtout dans cette Lorraine dont elle est originaire, mais non pas seulement. En général, les artistes lui ont donné des traits apaisés et recueillis plutôt que guerriers; ainsi à Bischoffsheim où elle découvre son armure, laissant pendre son bras sur le dos de sa monture en conférant une fonction purement décorative au bouclier qu'elle tient ; à Marlenheim elle semble chevaucher paisiblement, l'étendard à la main. D'autres saints ont été honorés uniquement parce que la ville était placée sous leur protection, en dehors de toute considération politique : Jean Népomucène, dont la statue ornait l'ancien monument aux morts de Rixheim (1925), était de ceux-là, tout comme Médard, patron de Boersch, qui bénéficie toutefois de l'avantage d'avoir été évêque de Noyon, ville détruite par les «Barbares » allemands, comme un orateur ne manque pas de le rappeler lors de l'inauguration (le 4 novembre 1923).

\section{L'épigraphie}

$\mathrm{Du}$ fait du statut politique du Reichsland entre 1914 et 1918, la quasi-totalité des soldats alsaciens ne furent pas des «poilus ». Et pourtant, l'accent est nettement mis dans l'entre-deux-guerres sur les engagés volontaires dans l'armée française, bien moins nombreux que la foule des incorporés dans l'armée allemande. La proportion des uns et des autres est difficile à établir et l'imprécision des chiffres en dit long sur leur importance politique: de 17 à 25000 Alsaciens-Lorrains auraient porté l'uniforme français et 380000 le Feldgrau. Même dans l'hypothèse la plus haute, autour de $5 \%$ des combattants seulement ont donc été soldats français. Cette histoire particulière de l'Alsace explique l'absence du traditionnel " Mort pour la France " sur les monuments (encore qu'il y ait des exceptions comme celle de Phalsbourg, vieille ville de garnison française dont sont originaires plusieurs généraux de la guerre de 19141918). Les inscriptions y sont généralement plus neutres, et aussi plus variées :

« La commune de Spicheren/ la ville de Riquewihr à ses enfants victimes des guerres de 1914-1918 et 1939-1945 »;

"La ville de Merlebach à ses morts »;

"Amnéville à ses victimes de guerre ";

« À nos morts » (Andlau, Bischheim, Mutzig, Sarralbe) ;

À Sélestat la municipalité a fait graver : "À tous ceux qui sont morts pour nos libertés » sur le monument de 1914-1918, phrase pourtant moins ambiguë que l'une de celles des monuments de Schiltigheim et d'Obernai : "Aux morts pour la Patrie ». A Bischwiller une phrase du poète 
officiel de la III $^{\mathrm{e}}$ République, Victor Hugo, est gravée à l'arrière du monument : «Entre les plus beaux noms, leur nom est le plus beau. »Vicsur-Seille a également choisi une citation d'où toute référence religieuse est absente: "Ceux que nous aimons et que nous avons perdus sont partout où nous sommes. " A Villé aucune inscription ne surmonte les noms des morts.

La double culture des Alsaciens-Lorrains s'exprime aussi par des inscriptions bilingues, mais on ne trouve pas d'exemple d'épigraphie allemande dans les villes, seulement dans des communes rurales, où le dialecte alsacien demeure jusqu'aux années 1960-1970 la langue de communication ordinaire, sinon unique, des habitants. Enfin, le latin est parfois utilisé : le mot "Pax» en lettres énormes attire aussitôt l'œil lorsqu'on se trouve face à l'obélisque de Barr; il est plus discret à Colmar. Ce thème se retrouve avec la statue de la Paix du monument de Mulhouse.

\section{Un culte civico-religieux}

Après 1918 se met en place un véritable culte, qui emprunte à la fois à la tradition civique (honorer des citoyens valeureux) et religieuse, puisque le clergé y trouve toute sa place. Dans les villes les cérémonies des années vingt et trente ne sont pas sans rappeler celles des cités grecques ou romaines, ou encore les fêtes civiques des communes du Moyen-Âge. L'inauguration d'un monument s'effectue selon une liturgie presque immuable. Sa date n'est en général pas choisie au hasard : le 11 novembre à Spicheren, par exemple. Elle est précédée d'une messe, puis d'une procession semi-religieuse (bannières de la paroisse et des sociétés catholiques d'une part) semi-profane (drapeau tricolore, mais aussi armoiries de la commune, bannières des associations d'anciens combattants, des pompiers, fanfare municipale, clubs sportifs d'autre part) comme aussi aux premiers temps de la Révolution de 1789 ou en 1848. Les acteurs de la cérémonie et les spectateurs appartiennent eux aussi aux deux sphères: sous-préfet, maire de la commune et des communes voisines, curé ou/ et pasteur, vétérans, autorités militaires, familles des victimes, notables, population. L'inauguration constitue un moment de communion dans le culte de la patrie et des chers morts confiés à la miséricorde divine.

Mais le culte du souvenir a eu ses ambiguïtés, surtout au cours de l'entre-deux-guerres. Dans les villes plus spécialement, les Alsaciens héros de la cause française apparaissent systématiquement sur le devant de la scène. Les vétérans de 1870, les engagés volontaires dans l'armée française, les médaillés militaires, les membres du Souvenir français, les anciens légionnaires sont les principaux personnages de ce «théâtre de la 
mémoire » dont les représentations les plus émouvantes ont lieu le 11 novembre, le jour de l'anniversaire de l'entrée des troupes libératrices (22 novembre dans le cas de Strasbourg) ou le 14 juillet. Est ainsi oblitéré le passé de l'écrasante majorité et exalté le sacrifice du petit nombre, replacé dans le cadre de celui de la nation tout entière. Ce choix, que le contexte de l'époque peut expliquer, présente l'inconvénient de culpabiliser ceux qui n'ont eu d'autre alternative que de se conformer au droit international, sous peine de mort.

Dans les villes plus petites c'est surtout la fête consensuelle de la Toussaint, où coïncident religion civique et religion catholique, qui reste le temps fort de l'année commémorative. Lorsque l'on honore les morts en ce jour, on se souvient avant tout de chrétiens et non de soldats qui ont porté l'uniforme français ou allemand.

\section{Les contestations du modèle traditionnel}

La première contestation, radicale, de la mémoire commémorative fut le fait des nazis. Au cours de l'annexion de fait de l'Alsace-Moselle, de l'été de 1940 à l'automne de 1944 (ou même le début de l'année 1945 dans certaines régions), les Allemands s'en sont pris un peu partout aux monuments qui rappelaient la présence française (ainsi le Poilu de Rouffach a été retiré de son socle, le monument de Thann a disparu). Ils ont en général démonté les Jeanne d'Arc (à Merlebach les habitants ont euxmêmes enlevé la figure de la Pucelle afin de la préserver de la destruction), ôté la statue de saint Jean Népomucène du monument de Rixheim. Leur vandalisme a pris très souvent un caractère nettement antichrétien. D'autres monuments ont été détruits ou endommagés par les combats. Ils portent ainsi dans leur « chair » les stigmates de l'histoire tourmentée de la région.

Après la Seconde Guerre mondiale la plupart des monuments détruits ou "escamotés " ont été reconstruits ou remontés. La fin des années 1940 est somme toute assez comparable à celle du lendemain de la Grande Guerre : exaltation patriotique (assortie cette fois d'une campagne contre le dialecte alsacien avec le slogan : "C'est chic de parler français »), renouveau religieux. Certaines différences sont toutefois à noter : d'abord l'importance des victimes civiles, qui se répartissent en deux grandes catégories (les habitants tués dans les bombardements et les combats de 1940 et de 1943-1945 d'une part, les déportés et internés d'autre part); ensuite le cas particulier des "Malgré-nous», Alsaciens et Mosellans incorporés de force, au mépris du droit cette fois, dans l'armée allemande à partir de 1942, morts ou disparus sur tous les champs de bataille de 
l'Europe. Ces soldats sont eux aussi considérés comme des victimes de guerre, broyées par les implaccables machines de mort nazie, mais aussi soviétique (car beaucoup sont décédés dans les camps russes, notamment celui de Tambov).

Malgré le caractère quelque peu «hétéroclite » des listes des morts de 1939-1945, conséquence d'une histoire encore plus complexe qu'en 1914-1918, le rituel préexistant continue de fonctionner pendant une vingtaine, voire une trentaine d'années. La date de la libération de la ville en 1944 ou 1945 se substitue simplement à celle de l'entrée des troupes françaises en 1918. Au 11 novembre s'ajoute désormais le 8 mai. Ces cérémonies continuent aujourd'hui, mais n'y assistent plus guère que les corps constitués, quelques fidèles anciens combattants et de rares membres plus jeunes de leur famille, des enfants des écoles, des curieux en petit nombre parfois. Partie intégrante du paysage urbain depuis si longtemps, le monument aux morts s'est fondu dans le décor. Il ne suscite plus en général qu'indifférence: les enfants jouent autour, les jeunes (ou moins jeunes) désœuvrés le fixent comme lieu de rendez-vous pour se retrouver ; il gêne parfois pour construire un parking, pour restructurer un centreville.

C'est que le grand bouleversement culturel et religieux de la fin des années 1960 a eu des conséquences également dans le domaine de la mémoire. Avec pour postulat une contestation générale de l'autorité, il a remis en cause des notions aussi essentielles et consensuelles autrefois que celles de patrie (et donc d'armée), de foi religieuse, de respect dû aux sacrifices consentis par les aînés. Pour une partie de la jeunesse « soixantehuitarde " les anciens combattants représentent tout ce qui est l'objet de leur rejet, voire de leur haine. L'affluence aux cérémonies devant les monuments aux morts n'a cessé depuis lors de baisser. Bien sûr un autre facteur d'explication doit être évoqué : celui de la distance avec l'événement. Il est évident que les parents, frères et sœurs, enfants de ceux dont les noms sont gravés dans la pierre se sentaient davantage concernés par les manifestations régulières qui étaient organisées dans les communes surtout lorsque la tombe de l'être cher se situait au loin ou, même, n'existait pas - que leurs petits et même arrière-petits-enfants, qui n'ont jamais connu ceux qui sont honorés sur les monuments.

\section{Le renouveau de la fin du siècle}

La fin de la décennie 1990 connaît pourtant un regain d'intérêt tout à fait inattendu pour la Première Guerre mondiale, sur fond d'attention très marquée accordée à la Seconde lors des anniversaires de 1994-1995 et 
de 2004-2005, qui revêtent un éclat tout particulier. Beaucoup de monuments aux morts sont alors "redécouverts ", même si ce sont parfois des aspects bien particuliers qui passionnent le grand public : a-t-on oublié d'y graver les noms de certains soldats, par exemple? Si oui, il n'est que temps de réparer cette injustice. Un petit phénomène de "troisième génération » apparaît: alors que les enfants des combattants se sont souvent peu préoccupés du passé militaire de leur père ou de leur oncle, petits-enfants, voire arrière-petits-enfants redécouvrent leur parcours. Les nombreuses sociétés savantes d'histoire locale qui quadrillent l'Alsace et la Moselle (plus que partout ailleurs en France) participent largement à ce renouveau, de même qu'un certain nombre de municipalités, désireuses de mettre en valeur le patrimoine local.

Cette recherche des racines et des spécificités de l'identité locale passe aussi par un désir de reconnaissance de plus en plus fort de ceux qui s'estiment "oubliés de l'Histoire ». C'est le cas surtout des Malgré-nous, dont certains développent des revendications presque "identitaires ", avec en 2003, puis en 2007 de nouveau, l'envoi d'une lettre au président de la République pour lui demander de faire solennellement repentance, au nom de la République, en raison des deux abandons successifs de l'Alsace et de la Lorraine mosellane en 1871 et 1940 (demande qui n'a reçu aucune réponse). D'autres se contentent de lutter plus sobrement contre l'oubli en faisant apposer sur les monuments aux morts des plaques qui rappellent spécifiquement les drames de la captivité et de la mort des incorporés de force à Tambov et dans d'autres camps en URSS.

Enfin, du fait de l'implaccable pyramide des âges, on constate depuis quelques années l'importance grandissante de la mémoire de l'Indochine et surtout de l'Algérie. La date du 19 mars (bien que contestée) s'inscrit désormais dans le calendrier commémoratif de la plupart des villes d'Alsace-Moselle. Les anciens d'AFN constituent en effet aujourd'hui les " gros bataillons" des associations d'anciens combattants, à commencer par la plus importante d'entre elles, l'UNC (Union nationale des combattants). Sur beaucoup de monuments - comme ceux de Ribeauvillé et de Rouffach - des plaques en mémoire des morts des TOE (Théâtre d'opérations extérieurs - Indochine, Afrique du Nord) ont été apposées.

\section{Les nouveaux lieux de mémoire}

Si le monument aux morts demeure donc, de nos jours encore, le lieu le plus clairement identifié de la mémoire des conflits des $\mathrm{XIX}^{\mathrm{e}}$ et $\mathrm{XX}^{\mathrm{e}}$ siècles dans les villes d'Alsace et de Moselle, les quelques constructions récentes ont des caractéristiques souvent assez différentes de celles des 
années vingt, ou même quarante et cinquante, bien que cette première époque ait déjà connu quelques variantes remarquables, comme le basrelief du monument de Rosheim qui appelait à la réconciliation francoallemande en figurant un poilu et un Feldgrau qui se tendaient la main (mais le soldat allemand n'était autre qu'un Alsacien dévoilant la cocarde tricolore qu'il cachait sous sa vareuse). À Lutterbach, après la disparition du premier monument aux morts dans les rénovations qui ont suivi le bombardement en 1944 de la basilique du Sacré Cœur (à l'intérieur de laquelle il se trouvait), la municipalité décide en 1988 d'ériger un groupe illustrant la prophétie d'Isaïe : "De leurs épées ils forgeront des socs de charrue. " Un artisan de grès rose empoigne le canon d'un char, émergeant d'un fatras d'armes diverses, et le transforme à coups de marteau en fleurs qui s'envolent vers le ciel. Nous sommes loin, ici, des monuments patriotiques d'autrefois.

Les débats qui agitent la société française actuelle, notamment ceux qui concerne l'immigration et l'intégration des immigrés de l'ancien Empire colonial, rejaillissent aussi sur la politique mémorielle. Le $1^{\mathrm{er}}$ novembre 2000 est inauguré devant l'entrée du cimetière militaire de StrasbourgCronenbourg, à l'initiative notamment d'un conseiller municipal d'origine algérienne, le colonel (de réserve) Meliani, un monument en hommage aux troupes d'Afrique et d'Outre-Mer qui ont largement contribué à la libération de l'Alsace pendant la Seconde Guerre mondiale. Les rapatriés d'Algérie ont quant à eux fait élever un monument au cimetière civil de ce même quartier de Cronenbourg dès 1972 «à la mémoire des pionniers et soldats morts et disparus en Afrique du Nord et Outre-Mer ». Une cérémonie s'y déroule le 26 mars, anniversaire de la fusillade de la rue d'Isly à Alger en 1962. A partir de 1992 une autre est aussi organisée le 5 juillet pour commémorer le massacre de plusieurs dizaines de civils français à Oran par l'ALN (en 1962 également).

Enfin, a été ouvert en juin 2005 dans la petite ville de Schirmeck le Mémorial d'Alsace-Moselle, consacré à l'histoire de la période qui court de 1870 (date du début de la guerre franco-prussienne) à 1953 (date du procès de Bordeaux des incorporés de force alsaciens dans la SS contraints de participer au massacre d'Oradour-sur-Glane en 1944). Ce nouveau lieu de mémoire, largement subventionné par les acteurs locaux (communauté de communes de Schirmeck et environs, conseils généraux du Bas-Rhin, du Haut-Rhin, de la Moselle, conseil régional d'Alsace), entend faire connaître leur histoire aux Alsaciens-Mosellans (surtout à ceux des jeunes générations) et également la faire découvrir aux autres Français et aux étrangers de passage (notamment allemands). S'inscrivant dans la ligne de l'Historial de Péronne ou du Mémorial de Caen, il présente une 
muséographie résolument moderne, sans beaucoup d'objets d'époque, mais avec la création "d'ambiances" au moyen de reconstitutions de lieux emblématiques (un wagon du train de l'évacuation des Alsaciens-Mosellans vers le Sud-Ouest en 1939, un champ de bataille en Russie, etc.). Il recueille aussi les archives que les particuliers veulent bien lui confier. Un projet de construction, le long des allées qui conduisent au Mémorial, de " mur de la mémoire », dans l'esprit de celui qui commémore à Washington les morts américains du Vietnam, est à l'étude. Il s'agirait de créer un lieu où les familles des plus de 40000 incorporés de force alsaciens et mosellans de la Seconde Guerre mondiale morts ou disparus pourraient venir se recueillir $^{11}$. Un mur virtuel est en cours de réalisation à Gravelotte, en Moselle.

\section{Conclusion}

En Alsace-Moselle comme dans le reste de la France la mémoire a connu de grandes mutations au cours des trente dernières années. Du fait de la désaffection croissante des jeunes générations pour les cérémonies civiques et de la déchristianisation qui a gagné aussi l'Alsace-Moselle (bien que l'attachement au Concordat y demeure fort), le culte "national et chrétien » qui entourait les monuments aux morts des villes et villages a perdu une grande partie de sa force. Seule la Toussaint garde une certaine vigueur.

Incontournables au cœur des villes, les monuments aux morts demeurent toutefois un symbole pour des Alsaciens et des Mosellans désireux de manifester leur enracinement à la fois local, national et, parfois, confessionnel. Ils expriment en effet la dualité et les particularités d'une histoire que beaucoup ne veulent pas oublier, même si elle a été depuis longtemps dépassée et même transcendée par la réconciliation franco-allemande et la construction de l'Europe, dont Strasbourg est l'une des capitales.

${ }^{11}$ Les Dernières Nouvelles d'Alsace, 15 décembre 2006. 
Žan-Noel Grandom, vanredni profesor savremene istorije

Univerzitet u Strazburu

\section{MESTA PAMĆENJA U SRCU GRADA: SPOMENICI STRADALNICIMA NA ISTOKU FRANCUSKE (ALZAS I MOZEL)}

\section{Rezime}

Između 1870 i 1945, Alzašani i deo Lorenaca ${ }^{12}$ (Mozelani $^{13}$ ) menjali su svoju nacionalnost četiri puta. Za vreme dva svetska rata 1914-1918. i 1939-1945, neki su nosili francusku, a većina nemačku uniformu. Prvi svetski rat 1918. godine završili su kao pobeđeni, da bi se 1919. našli u taboru pobednika na osnovu odluka Konferencije mira u Versaju koja ih je dodelila Francuskoj. U Drugom svetskom ratu 1940. godine doživeli su poraz kao i svi Francuzi, zatim je najveći broj njih uključen u nemačku vojsku (1942), da bi 1944-1945. bili oslobođeni od strane saveznika. Jedan alzaški humorista mogao je zato da kaže da je jedina uniforma koja im je po svoj prilici odgovarala bila uniforma ratnih zarobljenika. Kako je, dakle, izgrađeno pamćenje takve populacije? Kako je ono urezano na kamenu spomenika stradalnicima koji u srcu gradova Alzasa-Mozela svedoče danas o podvojenosti prošlosti ovih oblasti?

Podeljeno i suprotstavljeno nasleđe prošlosti istoka Francuske može da se analizira $u$ nekoliko hronoloških i problemskih celina. Razvoj značenja pojmova sećanje (souvenir) i pamćenje (mémoire) u francuskom društvu u drugoj polovini 20. veka pokazuje u kojoj meri su spomenici žrtvama stradalim $u$ ratovima bili odraz vremena $u$ kome su nastali. $\mathrm{Za}$ razliku od većine spomenika stradalnicima u Francuskoj, spomenici u Alzasu i departmanu Mozel najčešće nose hrišćanska obeležja. To može da se objasni posebnom zakonskom regulativom koja je primenjivana $u$ Alzasu-Mozelu posle njihove reintegracije u nacionalne okvire 1918. godine. Ipak, ikonografija i natpisi na ovim spomenicima su se razlikovali između većih i manjih gradova $u$ inače veoma urbanizovanoj oblasti Francuske. Poseban status ovih oblasti doprineo je da se između dva svetska rata uspostavi osoben "građansko-religijski“ kult u kome je sveštenstvo imalo značajnu ulogu. Uspostavljeni model pamćenja prošlosti radikalno je izmenjen za vreme aneksije Alzas-Mozela od strane nacističke

\footnotetext{
${ }^{12} \mathrm{U}$ smislu stanovnika francuskih regija Alzasa i Lorene.

${ }^{13} \mathrm{U}$ smislu stanovnika francuskog departmana Mozel koji pripada regiji Lorena.
} 
Nemačke, koja je uništavala spomenike koji su podsećali na francusko prisustvo. Period neposredno posle Drugog svetskog rata i povratka ovih oblasti Francuskoj bio je sličan razdoblju posle Prvog svetskog rata: insistiralo se na patriotskom ushićenju ali i obnovi religijskih osećanja. Međutim, veliko kulturološko i religijsko previranje krajem šezdesetih godina XX veka imalo je posledice i u domenu pamćenja. $\mathrm{Na}$ osnovu postulata opšteg osporavanja svakog autoriteta, stavljani su pod znak pitanja i pojmovi oko kojih je nekada uspostavljan konsenzus u društvu: otadžbina, vojska, vera i poštovanje prema žrtvama predaka. Od tada je priliv građana zainteresovanih za komemorativne svečanosti bio u stalnom opadanju. Ipak, krajem devedesetih godina XX veka došlo je do ponovnog oživljavanja interesovanja za Prvi svetski rat pod uticajem izražene pažnje koja je poklanjana Drugom svetskom ratu. Mnogi spomenici stradalnicima su „ponovo otkriveni“ zbog različitih pitanja koja su počela da interesuju široku publiku. U ovom periodu, javila su se i nova mesta pamćenja koja se znatno razlikuju od onih iz dvadesetih godina XX veka bilo da podsećaju na proces francusko-nemačkog pomirenja, aspekte francuske kolonijalne prošlosti ili lokalne istorije Alzas-Mozela.

U Alzas-Mozelu, kao i u ostatku Francuske, pamćenje prošlosti doživelo je velika previranja u poslednjih tridesetak godina. Zbog povećanja nezainteresovanosti mlađih generacija za javne svečanosti kao i usled procesa dehristijanizacije, „nacionalni i hrišćanski“ kult vezan za spomenike stradalnicima u Alzas-Mozelu izgubio je veliki deo svoje snage. Ipak, nezaobilazni u srcu gradova, spomenici stradalnicima su ostali važan simbol za Alzašane i Mozelane koji žele da ispolje svoju vezanost na lokalnom, nacionalnom i ponekad konfesionalnom nivou. Na taj način, oni izražavaju dvojnost i posebnost istorije koju mnogi ne žele da zaborave, čak i ako je ona odavno prevaziđena i uzvišena francusko-nemačkim pomirenjem i procesom stvaranja Evrope čiji je Strazbur jedan od centara.

Autor rezimea: Stanislav Sretenović 